WHATT

13,2

\section{Reflections on the theme issue outcomes}

\section{How is the hospitality and tourism industry in India responding to the dynamic} digital era?

Theme Editors, Sandeep Munjal and Anjana Singh share their reflections on the significance and outcomes of the theme issue with Managing Editor, Richard E. Teare.

\section{Overview}

This theme issue explored the impact and responses of Indian hospitality and tourism businesses in relation to the digital agenda. The articles it contains draw on industry-led research with active practitioner involvement, and they provide a balanced set of insights and perspectives as to how hospitality and tourism in India is changing and responding in the digital era. A list of the articles in this issue can be found in the Appendix.

\section{Why in your view, is your theme issue strategic question important?}

Since India's general election in 2014 and as an outcome, new central government political leadership, there has been a push for more extensive deployment of technology, characterized by a "digital India" development mandate. In addition to this government-led initiative, the penetration of mobile handsets and internet connectivity has made significant inroads. For example, "Reliance Jio", a venture by a prominent Indian conglomerate, has enabled cheap mobile-driven internet access for most Indians. The "smart city" initiative is another example of the government's technology drive across key urban centres in the country. Given this backdrop to the new pro-digital environment, there are clear implications for the hospitality and tourism industry in India. In the context of this theme issue, we wanted to explore how the industry has been affected and what are the responses to these changes in the current political-economic environment.

\section{Thinking about your theme issue plan and approach, what worked well?}

It was important to us to put together a theme issue with industry-led research content that provides perspectives from different directions in terms of how the hospitality and tourism industry in India is embracing the digital era. Further, we wanted to ensure that the article collection was informed by practitioner views and where possible, involve them in authorship of the papers. The WHATT theme issue plan itself was informed by ideas from a roundtable discussion between industry practitioners and academics. This worked well as we were able to discern the key stakeholders and debate the various aspects and issues that needed to be examined. The issue also needed to secure representation from key industry segments like hotels, restaurants and the broader tourism industry. Additionally, we felt it was important for a paper or two to examine the impact of the digital era from a customer perspective. As we look back, it is clear that the roundtable discussion worked really well for us because it underpinned our strategic question and helped us to define the main issues we wanted our writing team to explore.

\section{How did you engage with different stakeholder groups?}

The roundtable discussion format allowed us to engage with a fairly wide pool of practitioners from key industry segments like hotels, restaurant owners/managers and 
tourism policy experts, as well as tourism enthusiasts and even popular bloggers. While this helped us as theme editors to conceptualize the theme issue question and engage with potential authors/contributors, they too were able to connect with relevant stakeholders for the purpose of their research through focused groups or interviews. A mix of these approaches was deployed by most contributors to the theme issue.

What were the highlights from stakeholder group interactions?

The key takeaways from the industry practitioner perspective related to broad acceptance with respect to the deployment and use of technology-driven digital tools to improve efficiencies, enhance customer connectivity and in support of service quality. Outside of this general sense of accepting technology as a way of life, it was also clear that this stakeholder group did not want to make significant investments without clarity on benefits. Another highlight of stakeholder interactions was an observation that in terms of technology access and availability there was no lag between the western economic context and India; the gap had more to do with choice being exercised by Indian businesses with respect to what to accept and deploy and what to defer or wait and watch. The relevance of the research as well as the strategic question became quite apparent through the stakeholder group interactions.

\section{Thinking about your peer review process: What went well and why?}

The COVID-19 related lockdown was helpful in a unique way in that the writing team had more time to process feedback and additionally, respond to points arising from the theme editors. A very positive feature of this collaborative effort was that peer review comments from industry acted as a guide to the academic members of the team. The involvement of practitioners throughout the development and writing period meant that authors had access to real-time perspectives and feedback. Additionally, our roundtable practitioners and network of other professionals, facilitated industry access so that team members could conduct research for their theme issue article. It was great to see multiple rounds of inputs occurring and the on-going exchange of views throughout the process - from framing our strategic question and the roundtable discussion to creative and industry-focused data gathering, analysis and writing.

\section{What are the most significant outcomes of your theme issue in terms of the contributions to knowledge and/or professional practice?}

We are pleased to say that overall, the theme issue has generated some answers to our starting point theme issue question. The broad outcomes that emerged from discussions, literature review and industry-specific research are as follows:

- The Indian hospitality industry recognizes the role that technology-driven platforms can and will play in future, but from a practitioner perspective, the ways in which a return on investment will be derived must be established before the investment occurs.

- Deployment in hotels and restaurants (each with numerous segments) will vary from business to business and segment to segment, depending on how comfortable the leadership or ownership is with how the technology is working in support of the business.

- There are multiple challenges in what government has initiated including gaps in what is visible on the ground in relation to the "smart city" and "digital India" narratives. 
WHATT

13,2

298

- India will not copy the pattern of digital technology deployment in the West but will carve its own trajectory, based on value proposition and local context.

- Technology developers have much to do in terms of educating and convincing industry to deploy and use their products.

- One aspect or function of hospitality and tourism related businesses that has found quick acceptance is digital marketing because the related marketing tools (now well established) are in sync with the exploding social media space.

We hope that these main findings will help professionals and business leaders to assess and re-configure their strategies, allow policy-makers to introspect and to understand why loudly proclaimed initiatives from the government often fail to have the intended impact. More widely, we hope that international readers will derive a clear perspective on where the Indian hospitality and tourism stands in the digital era.

\section{What are the implications for management action and applied research arising from your theme issue outcomes?}

We think that hospitality business owners and leaders in India need to develop a comfortable working relationship with technology and the digital tools it provides. After this, they will possess the necessary insight needed to guide their businesses in the adoption and deployment of tools that add value. Digitalization will generate new data that will underpin good and consistent decision-making, but without the required tools and analysis, opportunities will be lost.

Although the theme issue sheds lights on key aspects of our strategic question, a segment-specific research effort would provide an interesting micro view on some of the aspects discussed in the issue. We think that it would make great sense for researchers to extend their efforts in that direction to derive more segment-specific findings and recommendations.

\section{Having served as a WHATT theme editor, what did you enjoy about the experience?}

The opportunity to serve as theme editors for WHATT is a fantastic experience. We found that when there is clarity on the overarching theme issue question, related questions emerge and it is possible to build a plan so that the rest of the process flows from this. It was a really a good learning experience too as we engaged with a wide range of stakeholders and contributors who in various ways, contributed to a big team effort.

Worldwide Hospitality and Tourism Themes (WHATT) aims to make a practical and theoretical contribution to hospitality and tourism development, and we seek to do this by using a key question to focus attention on an industry issue. If you would like to contribute to our work by serving as a WHATT theme editor, do please contact the Managing Editor, Dr Richard E. Teare via the Emerald website.

$$
\text { Sandeep Munjal and Anjana Singh }
$$
Theme Editors

\footnotetext{
About the Theme Editors

Sandeep Munjal is Professor and Director, Vedatya Institute, Gurgaon, in the National Capital Region (NCR) Delhi, India. Sandeep brings, to this theme issue, a combination of extensive industry and academic experience spanning more than 24 years.
} 
Anjana Singh is Head of the School of Hospitality and Tourism at Vedatya Institute. Anjana has than 16 years of experience in the hospitality industry and in academia and is Assistant Editor of the Journal of Services Research.

\section{Appendix 1. Theme issue contents (WHATT v13 n2 2021)}

How is the hospitality and tourism industry in India responding to the dynamic digital era?

\section{Anjana Singh and Sandeep Munjal}

Introduces the theme issue question and discusses the importance of digital technology and its role in customer engagement and marketing. It also identifies the role of human touch and traditional marketing by suggesting the appropriate mix and highlights the current digital trends in India's hospitality and tourism industry.

Techno-business strategies for enhancing guest experience in luxury hotels: a managerial perspective

Sonia Bharwani and David Mathews

Considers the emerging technological product and process innovations that are actively being used in hotels to deliver enhanced guest experiences. It also considers the challenges relating to technology adoption faced by Indian luxury hotels which have traditionally been driven by high-touch, unscripted and personalised service.

\section{Charting the role of digital platforms for cultural heritage tourism in India}

\section{Parul Munjal}

Explores various facets of interaction between conventional websites and digital applications to cultural heritage tourism in India. Given the rapid growth in the number of smart phone users in India, digital interfaces such as Android applications are easy to access and operate and could help create better heritage tourism experiences.

The transition from traditional to digital marketing: a study of the evolution of e-marketing in the indian hotel industry

\section{Rashmeet Kapoor and Kush Kapoor}

Analyzes the adoption and preferences of e-marketing tools in five star hotels in India by drawing on a roundtable discussion and interview with industry practitioners. The article also explores the scope for artificial intelligence and the challenges relating to its application.

\section{Adoption of digital marketing tools in independent businesses: Experiences of restau- rant entrepreneurs in India and UK}

\section{Swati Dabas and Savita Sharma and Kamal Manaktola}

Explores the experience of adoption of digital marketing and related tools by restaurant entrepreneurs or owners of restaurants in the UK and India. Additionally, the article probes restaurant owners' apprehensions during the adoption process, a step taken mainly with the objective of sustaining customer relationships in the long term. 
WHATT Kiosks as self-service technology in hotels: opportunities and challenges

13,2

Kanika Gupta and Sanjay Sharma

Explores the challenges and issues that hoteliers face while operating self-service kiosks together with customer perspectives and benefits. Among other findings, the study observes that anxiety about self-service technology and the reduction in traditional service reflect a transition phase with more benefits than disadvantages.

The impact of artificial intelligence and machine learning on the global economy and its implications for the hospitality sector in India

\section{Sudhanshu Bhushan}

Argues that the digital landscape of hospitality is realizing that artificial intelligence and machine learning is the next frontier of innovation, technology adoption and strategic advantage. From robots in kitchens to the marketing tools being used, the industry is at the threshold of the next level of technology-driven change.

Customer's digital advocacy: the impact of reviews and influencers in building trust for tourism and hospitality services

Kirti Dutta, Kirti Madan and Terjani Goyal

Explores the extent to which online or digital advocacy influences customer decision-making related to the purchase of travel and tourism services. The article also identifies the categories of influencers that stimulate purchases for travel and tourism.

\section{Positioning of tourist destinations in the digital era: a review of online customer feedback}

Gaurav Tripathy and Parul Wasan

Identifies features of online content that create engagement among consumers by exploring online customer feedback from the world's leading tourist websites. The article also examines the factors (based on customer reviews) that enable tourism industry professionals to promote and position India's tourist destinations.

Conclusion: Going digital is the only way forward for the indian tourism and hospitality industry

Sandeep Munjal and Anjana Singh

Reviews and summarizes the theme issue outcomes in relation to the strategic question: How is the hospitality and tourism industry in India responding to the dynamic digital era? 